\title{
Wedelolactone inhibits LPS-induced pro-inflammation via NF-kappaB Pathway in RAW 264.7 cells
}

Fang Yuan ${ }^{1 \dagger}$, Jie Chen ${ }^{2 \dagger}$, Ping-ping Sun ${ }^{2}$, Su Guan ${ }^{3}$ and Jing X $\mathrm{u}^{4^{*}}$

\begin{abstract}
Background: Wedelolactone (WEL), a major coumestan ingredient in Wedelia chinensis, has been used to treat septic shock, hepatitis and venom poisoning in traditional Chinese medicines. The objective of the study was to elucidate the anti-inflammatory effects and mechanism of WEL with a cellular model of lipopolysaccharide (LPS)-induced RAW 264.7 cells.

Results: To study the role of WEL in pro-inflammation, we measured key inflammation mediators and end products including nitric oxide (NO), prostaglandin E2 (PGE2), inducible nitric oxide synthase (iNOS), cyclooxygenase-2 (COX-2) and tumor necrosis factor-a (TNF-a) by using the Griess method, enzyme linked immunosorbent assay (ELISA) and Western blotting. Nuclear factor-kappaB (NF-KB) transcription activity was detected by luciferase reporter assay. The important pro-inflammatory transcription factors, NF-KB p65 and inhibitory kappaB alpha (IKB-a); and mitogen-activated protein kinases (MAPKs), including extracellular signal-regulated kinase (ERK), c-Jun N-terminal kinase (JNK) and p38 MAPK (p38) were analyzed by Western blotting. Our study showed that WEL $(0.1,1,10 \mu \mathrm{M})$ significantly inhibited the protein expression levels of iNOS and COX-2 in LPS-stimulated cells, as well as the downstream products, including NO, PGE2 and TNF-a. Moreover, WEL also inhibited LPS-induced NF-KB p65 activation via the degradation and phosphorylation of IKB- $\mathrm{a}$ and subsequent translocation of the NF-KB p65 subunit to the nucleus.
\end{abstract}

Conclusions: Our results revealed that WEL has a potential to be a novel anti-inflammatory agent targeting on the NF-KB signaling pathway.

Keywords: Wedelolactone (WEL), Popolysaccharide (LPS), Inflammation, Nuclear factor-KB (NF-KB), Macrophage

\section{Background}

Wedelolactone (WEL), a common ingredient in Wedelia chinensis and Eclipta prostrata, belongs to the flavonoids category of phytoestrogens [1,2] (structure shown in Figure 1). As a perennial herbal, WEL has been widely used to treat septic shock, hepatitis and venom poisoning in China [3-5]. Previous studies have shown that WEL has diverse pharmacological effects such as antihepatotoxic, antiandrogenic and anti-human immunodeficiency activities [6-8]. Kobori $\mathrm{M}$ et al. demonstrated that WEL

\footnotetext{
* Correspondence: gdpufredayuan@163.com

${ }^{\dagger}$ Equal contributors

${ }^{4}$ Department of Pharmacy, the Third Affiliated Hospital of Southern Medical University, Guangzhou 510630, China

Full list of author information is available at the end of the article
}

inhibits NF-kappaB (NF-kB) pathway by directly blocking phosphorylation and degradation of inhibitory kappaB alpha (IкB $\alpha$ ) [9]. Based on this result, Ruhland A et al. reported that WEL can reverse host cell resistance to parasite-induced apoptosis by inhibiting NF- $\kappa B$ signaling pathway [10]. Other results showed that WEL inhibits adipogenesis via activation of the ERK pathway [1]. Both WEL and demethyl-wedelolactone (DWL) showed trypsin inhibition effects in vitro [11]. Taken together, WEL has been identified as an anti-NF- $\mathrm{KB}$ translocation, growth inhibitory and pro-apoptotic agent in differentiated and cancer cells $[1,6,9,10]$. However, the precise mechanisms of its anti-inflammation effects have not been completely delineated.

Inflammation is an important host response to foreign challenge or tissue injury, which leads to the restoration

\section{() Biomed Central}




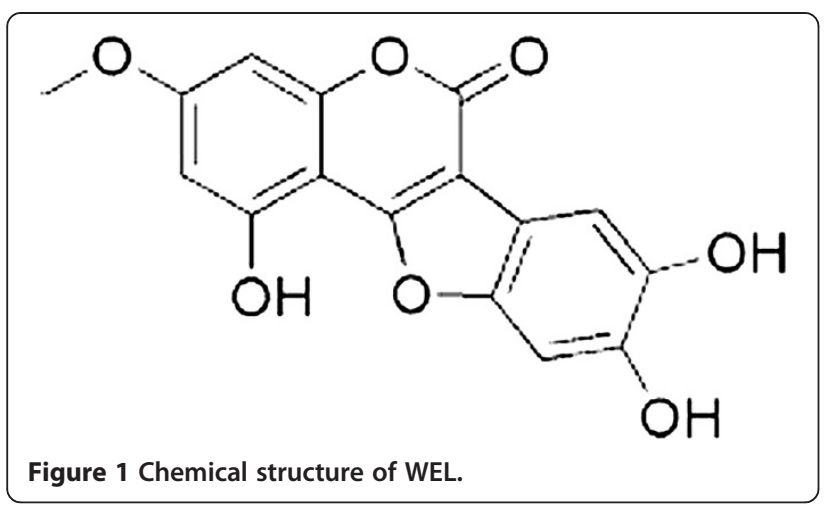

of tissue structure and function [12]. During the process, the activation of immune cells induced by proinflammatory cytokines up-regulates inflammation $[13,14]$. It is well known that macrophages, together with neutrophils and dendritic cells, play an important role in the innate immune response [15]. The key inflammatory mediators such as nitric oxide (NO), inducible nitric oxide synthase (iNOS), prostaglandin $\mathrm{E}_{2}\left(\mathrm{PGE}_{2}\right)$ and cyclooxygenase-2 (COX-2) and pro-inflammatory cytokine such as tumor-necrosis factor $\alpha$ (TNF- $\alpha)$ can be released by activated macrophages [16]. Lipopolysaccharide (LPS), a cell wall component of Gram-negative bacteria, has been reported to activate macrophages to produce inflammatory mediators such as iNOS, TNF- $\alpha$ and COX-2, mimicking the inflammatory reaction in vivo [14]. LPS triggers a serial of signal transduction events which lead to the activation of NF-KB and mitogen-activated protein kinase (MAPK) signaling pathway [17]. Herein, LPS induced macrophages is a well-established model for innate immunity study [18]. NF- $\mathrm{KB}$ has a pivotal role in immune and inflammatory responses through the regulation of pro-inflammatory cytokines, adhesion molecules, chemokines, growth factors and inducible enzymes, such as COX-2 and iNOS [12]. The activation of NF- $\mathrm{kB}$ in response to pro-inflammatory stimuli such as TNF- $\alpha$ has been characterized extensively. TNF- $\alpha$ stimulates the phosphorylation, ubiquitylation and subsequent degradation of inhibitor of ІкB $\alpha$ [12]. Mitogenactivated protein kinases (MAPKs) play a key role in the signaling pathways of cell proliferation, differentiation, survival, apoptosis and extracellular signal transduction to the nucleus $[19,20]$. MAPKs can be activated by Toll-like receptor 4 (TLR4) leading to the activation of nuclear translocation of NF- $\mathrm{kB}$ and finally initiates pro-inflammatory responses [21]. NF- $\mathrm{KB}$ is activated by phosphorylation of IкB $\alpha$ via activation of MAPKs such as ERK1/2, JNK and p38 subfamilies, and then migrates into the nucleus and activates the expression of inflammatory cytokines and mediators $[12,19,22]$. The activation of NF-KB in response to pro-inflammatory stimuli such as TNF- $\alpha$

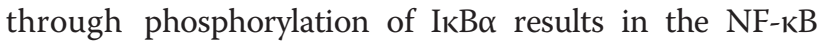

p65-p50 heterodimer to migrate into the nucleus and up-regulating the expression of pro-inflammatory and anti-apoptotic genes [12].

In the present study, we investigated the antiinflammatory effects of WEL in LPS-stimulated RAW 264.7 cells and examined whether WEL could inhibit inflammatory responses via suppression of the NF- $\mathrm{kB}$ and MAPKs signaling pathways.

\section{Methods}

\section{Cell culture and cell viability assay}

Raw 264.7 cell line was obtained from cell bank, Institute of Biochemistry and Cell Biology (Shanghai, China). Raw 264.7 cells were cultured in DMEM with $10 \%$ fetal bovine serum, in an incubator at $37^{\circ} \mathrm{C}, 5 \% \mathrm{CO}_{2}$ and $95 \%$ humidity. The cyctotoxic effects of WEL were evaluated in absence or presence of LPS by MTT assay. WEL was dissolved in 10\% dimethyl sulfoxide (DMSO) and added directly to culture media before the addition of LPS. The final concentration of DMSO never exceeded $0.1 \%$.

\section{Measurement of NO levels}

The nitrite concentration in the culture medium was measured by a Griess reaction test. Cells were plated as a density of $2 \times 10^{6}$ cells/well in 24-well culture plates and pretreated with or without indicated concentrations of WEL $(0.1,1,10 \mu \mathrm{M})$ or N-nitro-L-arginine methyl ester (L-NAME) $(100 \mu \mathrm{M})$ for $12 \mathrm{~h}$, and then incubated with LPS $(1 \mu \mathrm{g} / \mathrm{ml}) .100 \mu \mathrm{M}$ L-NAME, an inhibitor of $\mathrm{NO}$, was used as a positive control. After $20 \mathrm{~h}$ incubation, cells were washed three times to remove non-adherent cells. Then, $100 \mu \mathrm{l}$ of the Griess reagent was mixed with an equal volume of cell supernatant, the optical density at $540 \mathrm{~nm}$ was measured and the concentration of nitrite was calculated according to the standard curve generated from known concentrations of sodium nitrite.

\section{Measurement of PGE2 levels}

RAW 264.7 macrophages were subcultured in 24-well plates and pretreated with or without indicated concentrations of WEL $(0.1,1,10 \mu \mathrm{M})$ for $12 \mathrm{~h}$ or DX $(0.1 \mu \mathrm{M})$ for $1 \mathrm{~h}$, then incubated with LPS $(1 \mu \mathrm{g} / \mathrm{ml})$ for $20 \mathrm{~h}$. The accumulated $\mathrm{PGE}_{2}$ in the culture medium was measured using ELISA Kit (Cayman Chemical Company, Michigan, USA) according to the manufacturer's instructions. $0.1 \mu \mathrm{M}$ DX was used as a positive control.

\section{Measurement of TNF- $a$ levels}

The effects of WEL on the production of TNF- $\alpha$ were measured by ELISA. $2 \times 10^{6}$ RAW 264.7 cells (1\% serum starved) were seeded on 24-well plate at a density of $2 \times$ $10^{6}$ per well for over-night. Cells were pre-incubated with WEL $(0.1,1,10 \mu \mathrm{M})$ or DX $(0.1 \mu \mathrm{M})$ for $1 \mathrm{~h}$, then stimulated with $1 \mu \mathrm{g} / \mathrm{ml}$ LPS for another $20 \mathrm{~h}$. The 
cytokine concentrations were calculated according to the standard curve using recombinant cytokines in each ELISA kits. All measurements above were performed in triplicate.

\section{Transient transfection and luciferase reporter assay}

NF- $\mathrm{kB}$ reporter constructs were purchased from Clontech Laboratories, Inc. (Palo Alto, CA, USA). For the reporter assay, cells were seeded into 24-well plates at a density of $5 \times 10^{5}$ cells per well in $500 \mu \mathrm{l}$ of DMEM without antibiotics and incubated overnight. The cells in each well were transiently transfected with $200 \mathrm{ng}$ of luciferase reporter construct and $50 \mathrm{ng}$ of internal control plasmid of the pCMV- $\beta$-galactosidase reporter plasmid or empty expression vector pcDNA3 using lipofectamine TM 2000 reagent according to the manufacturer's procedures (Invitrogen, Carlsbad, CA, USA). Six hours after transfection, the cells were washed with phosphate-buffered saline to remove LiptofectamineTM 2000 complexes and then supplied with fresh medium (supplemented with fetal calf serum and phenol red free) and treated with WEL $(0.1,1$ and $10 \mu \mathrm{M})$ for $12 \mathrm{~h}$ before stimulation with LPS $(1 \mu \mathrm{g} / \mathrm{ml})$ for $20 \mathrm{~h}$. Subsequently, luciferase activities were measured in cell lysates using Dual Luciferase Reporter reagents following manufacturer's instruction (Promega, Madison, WI, USA).

\section{Western blotting analysis}

After treatment with various concentrations of WEL in presence or absence of $1 \mu \mathrm{g} / \mathrm{mL}$ LPS, cells were analyzed by immunoblotting. The treated cells were washed and scraped into cold phosphate-buffered saline (PBS) and centrifuged at $500 \times \mathrm{g}$ at $4^{\circ} \mathrm{C}$. The cell pellets were resuspended in lysis buffer and centrifuged to yield whole-cell lysates [23]. $20 \mu \mathrm{g}$ protein for each sample was separated by SDS-polyacrylamide gels with electrophoresis (Bio-Rad, Hercules, CA, USA) and the gel was transferred to PVDF membrane. The membrane was blocked with $10 \%$ skim milk for $1 \mathrm{~h}$ and then incubated overnight at $4^{\circ} \mathrm{C}$ with 1:2000 dilution of the corresponding primary antibody. After washing, the membranes were incubated with the appropriate secondary antibody conjugated to horseradish peroxidase. The membrane was immersed in the enhanced chemiluminescence solution for $60 \mathrm{sec}$. The gel images were visualized using ChemDoc (Bio-Rad, Hercules, CA) and densitometric analysis was performed with Quantity One 1-D Analysis software (Bio-Rad). The results are representative of three independent experiments.

\section{Drugs and solutions}

WEL (Purity $\geq 95 \%$, by HPLC) (Xidian Pharmaceutical Co., Ltd., Jilin, China) HEPES, LPS, N-nitro-L-arginine methyl ester and lipopolysaccharide (L-NAME) and 3-(4,5dimethylthiazol-2-yl)-2,5-diphenyl-tetrazolium bromide (MTT) (Sigma, St. Louis, MO, USA). Dulbecco's modified Eagle's medium (DMEM) and bovine serum albumin (BSA) (Gibco BRL, Gaithersburg, MD, USA). Griess reaction kit for Nitric Oxide (NO) (Jiancheng Co., Ltd., Nanjing, China). ELISA kits for detecting TNF- $\alpha$ (R\&D Systems, Inc., USA). PGE 2 ELISA Kit was obtained from Cayman Chemical Company (Ann Arbor, MI, USA). Trizol reagent (Invitrogen, Carlsbad, CA, USA). Antibodies specific for COX-2, iNOS, phospho-IkB $\alpha$, NF-кBp65, phospho-ERK1/2 and glyceraldehydes 3-phosphate dehydrogenase (GADPH) (Santa Cruz Biotechnology, Inc., Santa Cruz, CA, USA). Antibodies specific for MAPK family proteins (ERK1/2, phospho-p38, p38, phosphoJNK, JNK) (Cell Signaling Technology, Inc., Beverly, MA, USA). All other reagents were of analytical grade.

\section{Statistical analysis}

The results were expressed as mean \pm standard error of the mean (SEM) with the indicated number (n) of experiments. Differences between groups for continuous variables were evaluated with analysis of variance (ANOVA) and differences between two groups were analyzed using unpaired Student's $t$-test (SPSS version 10.0; Chicago, IL). Statistical significance was set as $p<0.05$.

\section{Results}

\section{Effects of WEL on cell viability}

The cytotoxicity of WEL in RAW 264.7 cells was measured by MTT assay (Figure 2). The results showed that WEL did not affect cell viability at a concentration of $0.1 \mu \mathrm{M}$ to $100 \mu \mathrm{M}$ regardless of the presence of LPS for $20 \mathrm{~h}$. Therefore, a concentration of 0.1 to $10 \mu \mathrm{M}$ of WEL was used in all experiments.

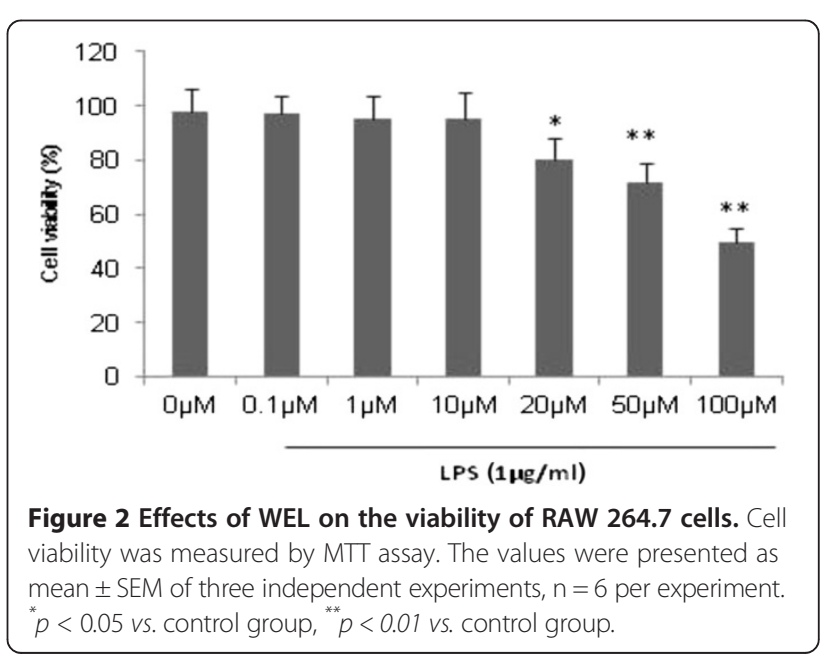




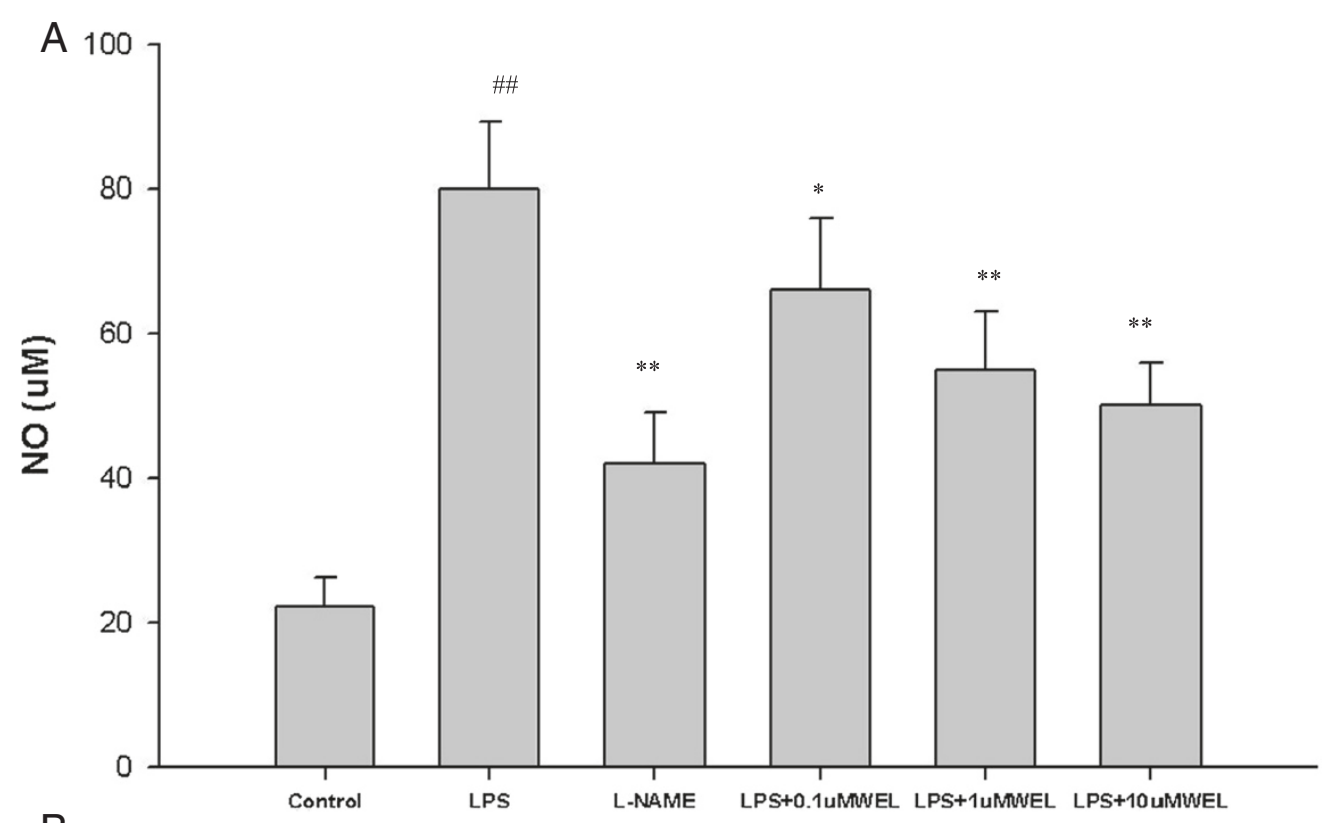

B

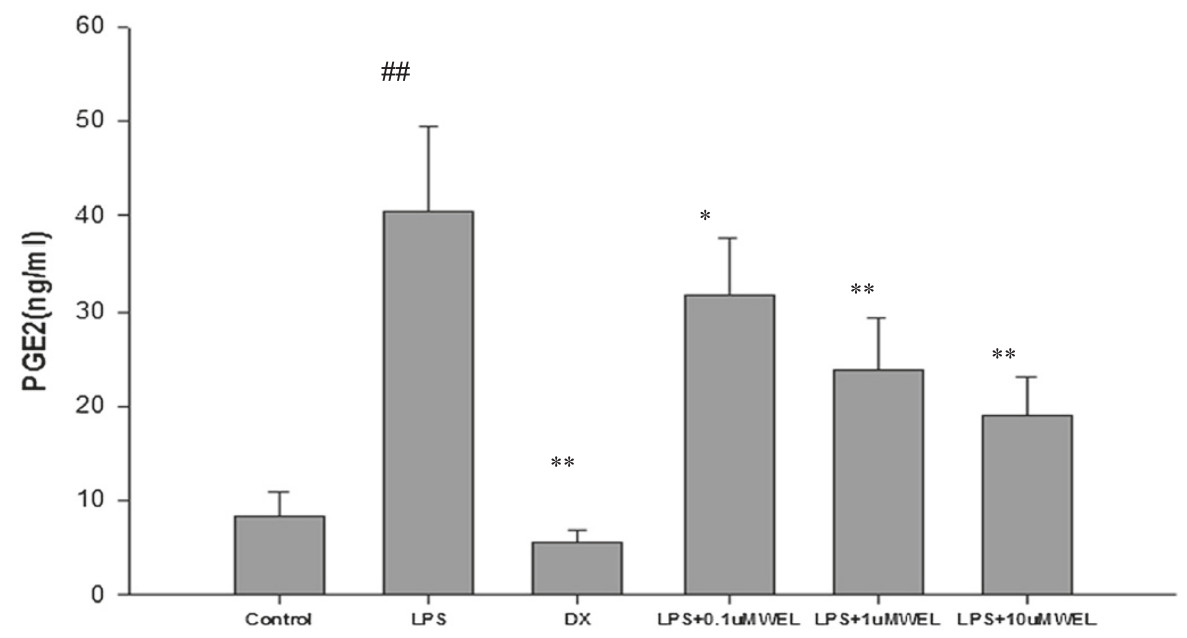

C

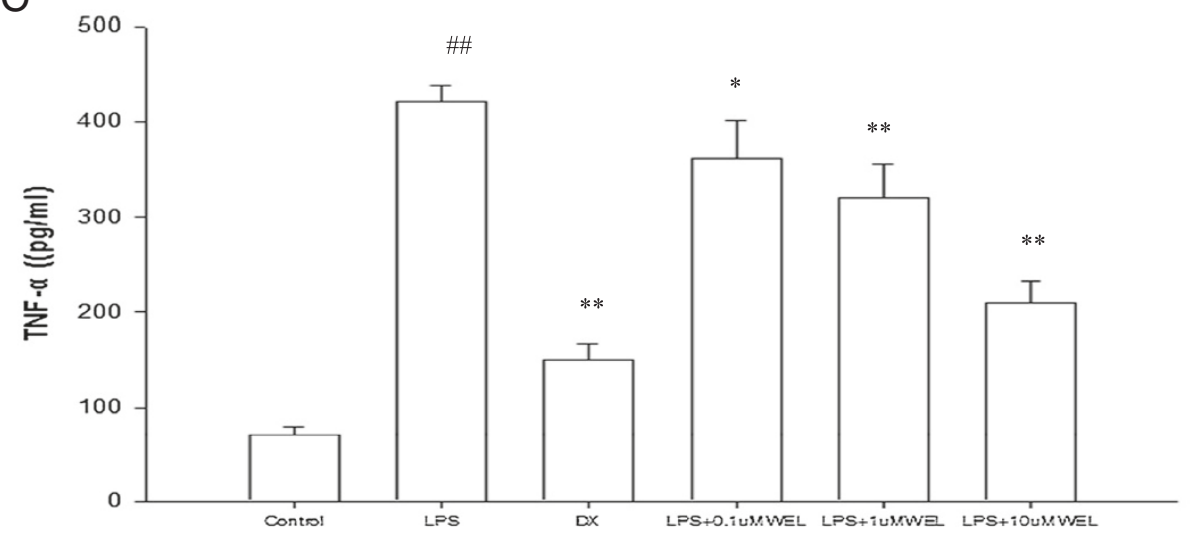

Figure $\mathbf{3}$ (See legend on next page.) 
(See figure on previous page.)

Figure 3 Effects of WEL on LPS-induced NO, PGE2 and TNF-a production in RAW 264.7 macrophages. (A) Cells were treated with the indicated concentrations of WEL $(0,0.1,1$, or $10 \mu \mathrm{M})$ or $100 \mu \mathrm{M}$ L-NAME for $12 \mathrm{~h}$, respectively, and then incubated with LPS $(1 \mu \mathrm{g} / \mathrm{ml})$ for $20 \mathrm{~h}$. $100 \mathrm{\mu M}$ L-NAME group was set as positive control. The nitrite production was measured by the Griess reaction. (B, C) Cells were treated with the indicated concentrations of WEL $12 \mathrm{~h}$ or $0.1 \mathrm{DX}(0.1 \mu \mathrm{M})$ for $1 \mathrm{~h}$, respectively, and then incubated with LPS $(1 \mu \mathrm{g} / \mathrm{ml})$ treatment for $20 \mathrm{~h}$. The PGE2 and TNF- $a$ concentration were determined by ELISA kit. The values were presented as mean \pm SEM. of three independent experiments. $n=6$ per experiment. ${ }^{*} p<0.05$ vs. LPS group and ${ }^{* *} p<0.01$ vs. LPS group. ${ }^{\#} p<0.05$ vs. none LPS control group. ${ }^{\# \#} p<0.01$ vs. none LPS control group.

\section{Effects of WEL on NO and PGE2 production in LPS-stimulated cells}

The potential anti-inflammatory effects of WEL on LPSstimulated $\mathrm{NO}$ and $\mathrm{PGE}_{2}$ production were examined in RAW 264.7 macrophages by pretreating cells with various concentrations of WEL for $12 \mathrm{~h}$ before stimulation with $1 \mu \mathrm{g} / \mathrm{mL}$ LPS for $20 \mathrm{~h}$. NO and $\mathrm{PGE}_{2}$ concentrations in the culture medium were measured by Griess reagent and ELISA, respectively. As shown in Figure 3, $\mathrm{NO}$ and $\mathrm{PGE}_{2}$ production was remarkably induced in LPS-stimulated RAW 264.7 macrophages when compared with un-stimulated negative controls, while pretreatment with WEL significantly prevented this increase in a dose-dependent manner. This inhibitory effect was achieved with non-cytotoxic concentrations of WEL.

Effects of WEL on TNF-a production in LPS-stimulated cells To study the effects of WEL on LPS-induced inflammatory related cytokine production, such as TNF- $\alpha$ production in RAW 264.7 cells, cells were pretreated for $12 \mathrm{~h}$ with various concentrations of WEL, followed by

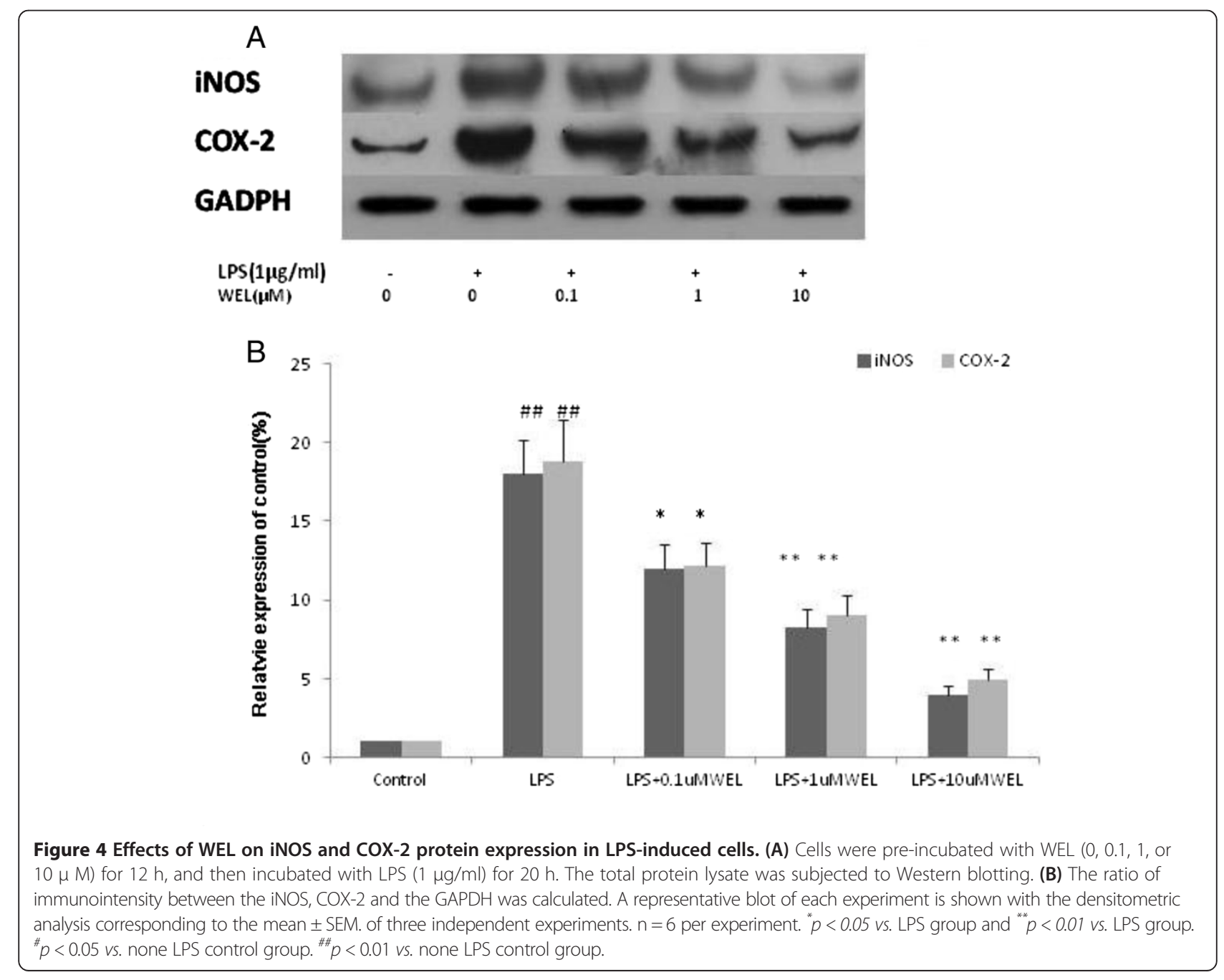



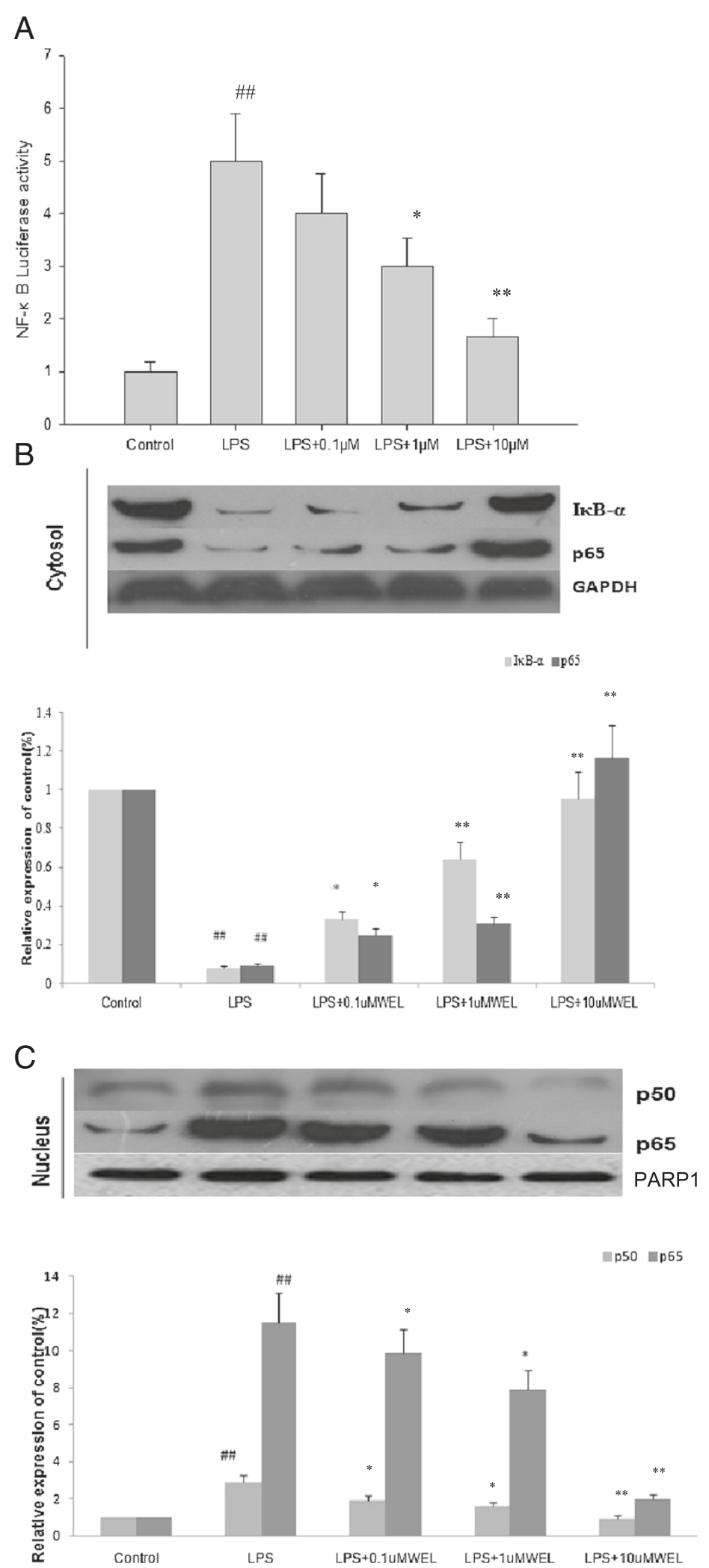

Figure $\mathbf{5}$ (See legend on next page.) 
(See figure on previous page.)

Figure 5 Effects of WEL on LPS-induced NF-KB transcriptional activity via suppression of IKB- $a$ degradation and nuclear translocation of the p65 and p50 subunits in RAW 264.7 cells. (A) Cells were transiently co-transfected with pNF-KB-Luc reporter plasmid and then were pretreated with the indicated concentrations of WEL for $12 \mathrm{~h}$. LPS $(1 \mu \mathrm{g} / \mathrm{ml})$ was then added and cells were further incubated for $20 \mathrm{~h}$. The cells were harvested and then the luciferase activities were determined by using the dual luciferase report assay system. (B, C) Cells were pretreated with the indicated concentrations of WEL for $12 \mathrm{~h}$ and then stimulated with LPS $(1 \mu \mathrm{g} / \mathrm{ml})$ treatment for $30 \mathrm{~min}$. Cytosol (B) and nuclear (C) protein were determined by Western blot assay using anti-lkB-a, NF-KB p50, and NF-KB p65. GAPDH and PARP1 were used as internal controls for Western blotting. A representative blot of each experiment was shown with the densitometric analysis corresponding to the mean $\pm \mathrm{SEM}$. of three independent experiments. $\mathrm{n}=6$ per experiment. ${ }^{*} p<0.05$ vs. LPS group and ${ }^{* *} p<0.01$ vs. LPS group. ${ }^{\#} p<0.05$ vs. none LPS control group. ${ }^{\# \#} p<0.01$ vs. none LPS control group.

treatment with LPS $(1 \mu \mathrm{g} / \mathrm{ml})$ for $20 \mathrm{~h}$. The production of TNF- $\alpha$ induced by LPS was evaluated by ELISA. Our result showed that WEL dose-dependently blocked the expression of the pro-inflammatory cytokine TNF- $\alpha$ (Figure 3).

\section{Effects of WEL on iNOS and COX-2 protein expression in LPS-stimulated cells}

Based on the findings above, we investigated whether the inhibition of WEL on $\mathrm{NO}$ and $\mathrm{PGE}_{2}$ production was related to down-regulation of iNOS and COX-2. Cells were pretreated with the indicated concentration of WEL for $12 \mathrm{~h}$ followed with LPS $(1 \mu \mathrm{g} / \mathrm{ml})$ treatment for another $20 \mathrm{~h}$. The protein levels of iNOS and COX-2 were significantly up-regulated in response to LPS, and WEL inhibited the expression of these proteins in a dosedependent manner (Figure 4). These results showed that WEL was able to inhibite the expression of iNOS and COX-2 enzymes, which in turn reduce the production of $\mathrm{NO}$ and $\mathrm{PGE}_{2}$, the two key mediators of inflammation, respectively.

\section{Effects of WEL on LPS-mediated NF-кB transcriptional activity via suppression of IKB- $\alpha$ degradation and nuclear translocation of the p65 and p50 subunits in RAW 264.7 cells} $\mathrm{NF}-\mathrm{kB}$ plays a pivotal role in regulation of the expression of iNOS, COX-2 and inflammatory cytokines such as TNF- $\alpha$ [12]. The heteromeric NF- $\kappa$ B complex is sequestered in the cytoplasm as an inactive precursor, combined with an inhibitory $I \kappa B-\alpha$ protein. Activation of NF- $\mathrm{kB}$, an important transcription factor in the inflammatory response, occurs after the phosphorylation, ubiquitination and proteolytic degradation of $\mathrm{I} \kappa \mathrm{B}-\alpha$ [24]. To investigate the underlying mechanism of the inhibition of WEL on iNOS and COX-2 protein expression in LPS-stimulated cells, luciferase reporter assay was used to explore the effects of WEL on NF$\mathrm{kB}$-dependent reporter gene expression following LPS treatment. RAW 264.7 cells were transiently cotransfected with a pNF-kB-leu reporter vector with four spaced NF$\kappa \mathrm{B}$-binding sites into the pLuc-promoter vector and then stimulated with $1 \mu \mathrm{g} / \mathrm{ml}$ LPS with or without WEL. WEL significantly reduced the level of NF- $\mathrm{kB}$ luciferase activity induced by LPS in a dose-dependent manner (Figure 5A). To further investigate whether WEL regulates the NF-kB pathway, the cytoplasmic protein level of IkB- $\alpha$ was measured by western blotting after cells were pretreated with the indicated concentrations of WEL for $12 \mathrm{~h}$ and stimulated with LPS $(1 \mu \mathrm{g} / \mathrm{ml})$ for $30 \mathrm{~min}$. The results showed that WEL inhibited the phosphorylation and degradation of the IкB- $\alpha$ protein after LPS treatment. Because p65 and p50 are the major subunits of the NF $-\kappa B$ heterodimer, the translocation of p 65 and $\mathrm{p} 50$ subunits from the cytoplasm to the nucleus after being released from $I_{k} B-\alpha$ were investigated. As shown in Figure 5B and $\mathrm{C}$, the concentrations of p65 and p50 subunits were decreased in the cytoplasm and increased in nucleus after LPS treatment, pretreatment with WEL reversed these trends in a dose-dependent manner. Taken together, these findings demonstrated that WEL suppressed the expression of iNOS and COX-2 at least in part via NF-kB-dependent mechanism.

\section{Effects of WEL on the activation of ERK1/2, JNK and p38 in LPS-stimulated cells}

Three MAPKs, ERK, p38 and JNK, are known to be activated by LPS. MAPKs play an important role in the transcriptional regulation of LPS-induced expression of iNOS and COX-2 via activation of the transcription factor NF-kB [25]. Thus, we investigated the effect of WEL on the activation of ERK1/2, JNK and p38. After cells were pretreated with the indicated concentrations of WEL for $12 \mathrm{~h}$ and stimulated with LPS $(1 \mu \mathrm{g} / \mathrm{ml})$ for $30 \mathrm{~min}$, the expression of ERK1/2, JNK, and p38 was analyzed by Western blotting. As shown in Figure 6, WEL pretreatment obviously increased phosphorylation of ERK1/2 (p-ERK1/2) and slightly enhanced phosphorylation of JNK (p-JNK). At the same time, WEL was not observed to have any effect on the LPS-induced phosphorylation of p38 MAPK. These results indicated that the inhibitory effect of WEL on TNF- $\alpha$, NO and $\mathrm{PGE}_{2}$ was mediated possibly via the downstream MAPKs pathway but independent of the activation of MAPKs. NF-kB activation rather than the phophorylation of MAPKs may be involved in WEL reduced cytokines production. 

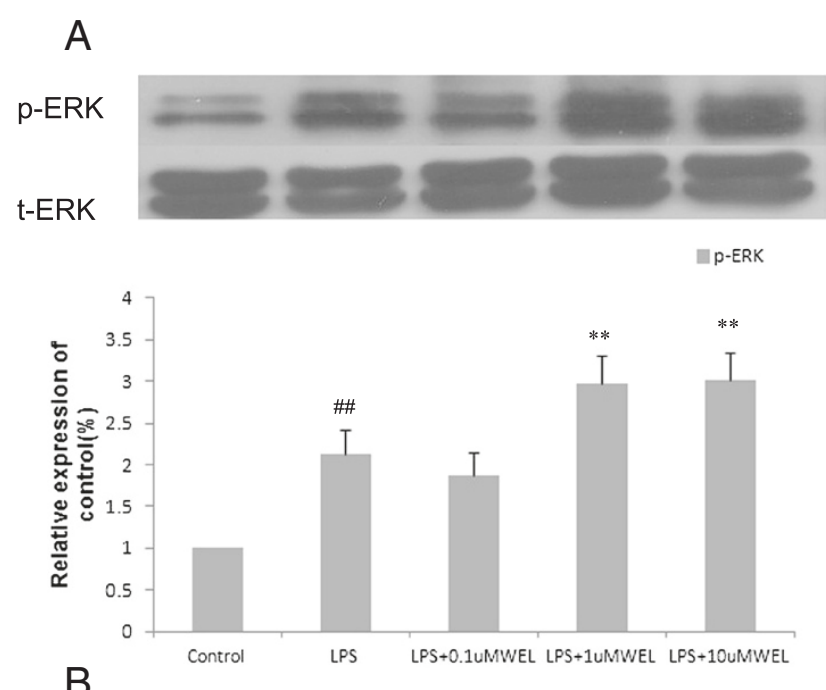

B

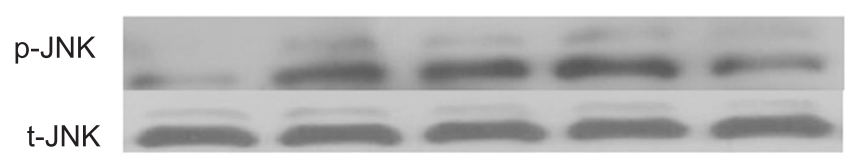

- $\mathrm{p}-\mathrm{JNK}$

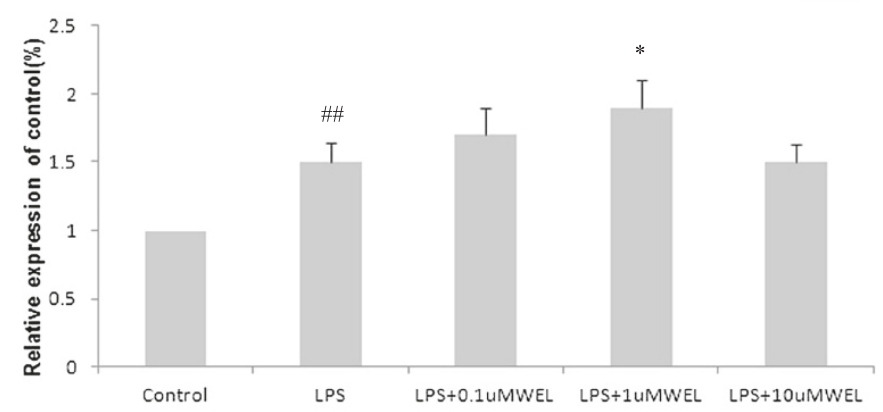

C

p-38

$\mathrm{t}-38$
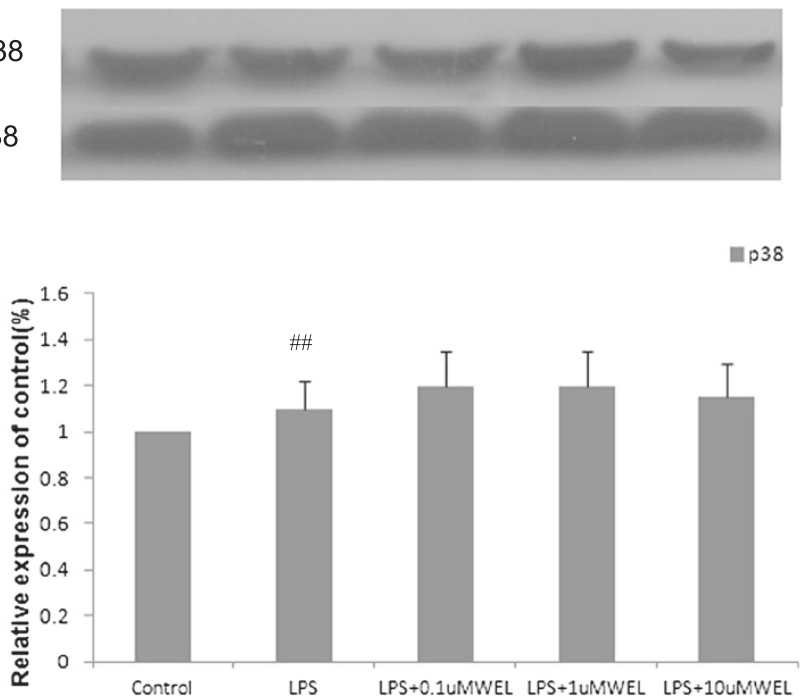

Figure 6 (See legend on next page.) 
(See figure on previous page.)

Figure 6 Effects of the WEL on the activation of ERK1/2 (A), JNK (B) and p38 (C) in LPS-stimulated cells. Cells were pre-incubated with WEL for $12 \mathrm{~h}$, and then incubated with LPS $(1 \mu \mathrm{g} / \mathrm{mL})$ for $30 \mathrm{~min}$. The total protein lysate was subjected to Western blotting analysis. The ratios of immunointensity of p-ERK1/2, p-JNK and p-p38 were calculated, respectively. Total ERK1/2, JNK and p38 (t-ERK1/2, t-JNK and t-p38) were used as a control of the protein amount in the same samples. A representative blot of each experiment is shown with the densitometric anaylsis corresponding to the mean \pm SEM. of three independent experiments. $n=6$ per experiment. ${ }^{*} p<0.05$ vs. LPS group and ${ }^{* *} p<0.01$ vs. LPS group. ${ }^{*} p<0.05$ vs. none LPS control group. ${ }^{\# \#} p<0.01$ vs. none LPS control group.

\section{Discussion}

WEL belongs to the flavonoids category of phytoestrogens in Eclipta prostrata and Wedelia chinensis. We investigated its anti-inflammatory activity and underlying mechanism of WEL in LPS stimulated RAW 264.7 cells. WEL has been identified as an anti-inflammatory, growth inhibitory and pro-apoptotic agent in differentiated cells and cancer cells $[1,6,9,10]$. Previous findings that WEL inhibited IKK activity and caspase-11 expression which resulted in the activation of NF-kB pathway suggested that WEL could be a potential lead compound in antiinflammatory therapy [9]. However the mechanisms of anti-inflammatory effects of WEL have not been completely delineated. Thus, our study aimed to elucidate the mechanisms underlying the anti-inflammatory effects of WEL.

It is well-known that $\mathrm{NO}$ and $\mathrm{PGE}_{2}$ play critical roles in the activation of macrophages, and they are closely associated with acute and chronic inflammation [12,26]. Therefore, to study the suppression of $\mathrm{NO}$ and $\mathrm{PGE}_{2}$ by iNOS and COX-2 is very important in the development of antiinflammatory agents $[23,27]$. Here, we demonstrated that WEL can dose-dependently inhibit LPS-induced NO and $\mathrm{PGE}_{2}$ production in RAW 264.7 macrophages. Consistent with these findings, WEL also suppressed LPS-induced expression of iNOS and COX-2 at the protein levels in RAW 264.7 macrophages, which suggested that WEL-induced reduction of $\mathrm{NO}$ and $\mathrm{PGE}_{2}$ may be due to transcriptional suppression of iNOS and COX-2 genes. TNF- $\alpha$ plays a critical role in innate immune responses and it is the principal mediator in responses to LPS stimulated tissue injury and shock. Therefore, we also investigated the effect of WEL on LPS-inducible TNF- $\alpha$ expression [23]. Our results showed that WEL significantly suppressed TNF- $\alpha$ production in LPS-stimulated RAW 264.7 cells.

NF- $\kappa B$ plays a pivotal role in the regulation of the expression of iNOS, COX-2 and inflammatory cytokines such as TNF- $\alpha$ [12]. Activation of NF- $\mathrm{B}$ involves in the phosphorylation and subsequent proteolytic degradation of the inhibitory protein $I_{\kappa} B$ by specific $I_{\kappa} B$ kinases. The free NF- $\mathrm{KB}$ (a heterodimer of $\mathrm{p} 50$ and p65) then passes into the nucleus, where it binds to NF- $\mathrm{KB}$ site in the promoter regions of genes for inflammatory proteins such as cytokines, enzymes, and adhesion molecules [24]. Therefore, we examined the effect of WEL on the phosphorylation of I $\mathrm{I} B-\alpha$ and the nuclear translocation of p65 and p50 subunits into the nucleus. Our results showed that LPS treatment caused the decrease of p65 and p50 in the cytoplasm and increase in nucleus, and this effect can be reversed by the pretreatment with WEL in a dose-dependent manner. The present study showed that WEL inhibited LPS-induced NF- $\mathrm{kB}$ activation through the suppression of the phosphorylation and degradation of $I \kappa B-\alpha$ and subsequent effects on the nuclear translocation of the subunit of NF-kB in RAW 264.7 macrophages.

The MAPKs pathway is one of the most ancient and evolutionarily conserved signaling pathway and plays essential regulatory roles in both innate and adaptive immune response [17]. MAPKs play an important role in the transcriptional regulation of LPS-induced expression of iNOS and COX-2 [25]. LPS stimulation of cytokines production in human monocytes is involved in several intracellular signaling pathways that include three MAPK pathways: ERK 1 and 2, JNK and p38 and IKK-NF-kB pathway [25]. Several studies have shown that some active compounds inhibit LPS-induced inflammatory cytokines production via the down-regulation of NF- $\mathrm{kB}$ and MAPKs activities in RAW 264.7 cells [20,26,28]. Thus, we investigated the effect of WEL on activation of ERK1/2, JNK and p38 in LPS-stimulated cells.

Our results showed that the phophorylation of JNK and ERK in response to LPS were induced with WEL treatment, whereas p38 phosphorylation was not affected. These results indicated that anti-inflammatory mechanism of WEL was mediated possibly via the downstream MAPKs pathway but independent of the activation of MAPK signaling pathway. NF-kB activation rather than the phophorylation of MAPKs may be involved in WEL reduced cytokines production. Similar phenomena were also found in the anti-inflammatory effect of Cucurbitacin E, which was reported by Qiao J [29]. However, the role and the underlying mechanism of WEL-induced activation of MAPKs in LPS-stimulated cells are remained to be further elucidated.

In conclusion, WEL was shown to inhibit the production of $\mathrm{NO}$ and $\mathrm{PGE}_{2}$ as well as their upstream enzymes iNOS and COX-2 at protein level through inhibition of IкB- $\alpha$ phosphorylation and p65 nuclear translocation in LPS-induced RAW 264.7 cells. The inhibition of iNOS and COX-2 expression was mediated independent of the MAPK. 


\section{Conclusions}

The results of our study indicated that WEL exerted anti-inflammatory effects by suppressing the NF- $\mathrm{kB}$ pathway. However, the effects of WEL on MAPKs pathway need to be elucidated in further study.

\section{Abbreviations}

WEL: Wedelolactone; LPS: Lipopolysaccharide; DX: Dexamethason; NO: Nitric oxide; PGE2: Prostaglandin E2; L-NAME: N-nitro-L-arginine methyl ester and lipopolysaccharide; iNOS: Inducible nitric oxide synthase; COX-2: Cyclooxygenase-2; TNF-a: Tumor necrosis factor-a; ELISA: Enzyme linked immunosorbent assay; NF-kB: Nuclear factor-kappaB; IKB-a: Inhibitory kappaB alpha; MAPKs: Mitogen-activated protein kinases; ERK: Extracellular signal-regulated kinase; JNK, c-Jun: N-terminal kinase; p-ERK1/2 and p-JNK: Phosphorylation of ERK1/2 and JNK; T-ERK1/2: t-JNK and t-p38, total ERK1/2, JNK and p38.

\section{Competing interests}

The authors declare that they have no competing interests.

\section{Authors' contributions}

FY and JC made substantial contributions to the conception and design, analysis and interpretation of data, drafting of the manuscript, and were responsible for all experiments. FY and JC contributed equally to this work. $\mathrm{Pp} \mathrm{S}$ contributed to the cell culture, was involved in molecular analyses of cells (Wester blotting, ELISA, Measurement of TNF-a, NO and PGE ) $^{\text {S SG }}$ performed Transient Transfection and Luciferase Reporter Assay and critically revised the manuscript for important intellectual content. JX contributed to the conception and design, and critically revised the manuscript for important intellectual content. JX contributed to the conception and design, and critically revised the manuscript for important intellectual content. All authors have given final approval of the manuscript.

\section{Acknowledgements}

This study was supported by the Natural Scientific Foundation of China (30972917), the Hospital Pharmacy Foundation of Gongdong Province (2010A13) and the Medical Scientific Research Foundation of Guangdong Province (A2013193).

\section{Author details}

${ }^{1}$ Department of Pharmacology, School of Pharmacy, Guangdong Pharmaceutical University, Guangzhou 510006, China. ${ }^{2}$ Department of Pharmacy, the First Affiliated Hospital of Sun Yat-sen University, Guangzhou 510080, China. ${ }^{3}$ School of Bioscience and Biotechnology, South China University of Technology, Guangzhou 510006, China. ${ }^{4}$ Department of Pharmacy, the Third Affiliated Hospital of Southern Medical University, Guangzhou 510630, China.

Received: 9 May 2013 Accepted: 23 October 2013

Published: 31 October 2013

\section{References}

1. Lim S, Jang HJ, Park EH, Kim JK, Kim JM, Kim EK, et al: Wedelolactone inhibits adipogenesis through the ERK pathway in human adipose tissue-derived mesenchymal stem cells. J Cell Biochem 2012, 113:3436-3445.

2. Mors WB, do NMC, Parente JP, da SMH, Melo PA, Suarez-Kurtz G: Neutralization of lethal and myotoxic activities of South American rattlesnake venom by extracts and constituents of the plant Eclipta prostrata (Asteraceae). Toxicon 1989, 27:1003-1009.

3. Diogo LC, Fernandes RS, Marcussi S, Menaldo DL, Roberto PG, Matrangulo PV, et al: Inhibition of snake venoms and phospholipases $A(2)$ by extracts from native andgenetically modified Eclipta alba: isolation of active coumestans. Basic Clin Pharmacol Toxicol 2009, 104:293-299.

4. Idris Al, Libouban $\mathrm{H}$, Nyangoga $\mathrm{H}$, Landao-Bassonga $\mathrm{E}$, Chappard D, Ralston SH: Pharmacologic inhibitors of IkappaB kinase suppress growth and migration ofmammary carcinosarcoma cells in vitro and prevent osteolytic bone metastasis invivo. Mol Cancer Ther 2009, 8:2339-2347.

5. Tsai CH, Lin FM, Yang YC, Lee MT, Cha TL, Wu GJ, et al: Herbal extract of Wedelia chinensis attenuates androgen receptor activity andorthotopic growth of prostate cancer in nude mice. Clin Cancer Res 2009, 15:5435-5444.

6. Wagner H, Geyer B, Kiso Y, Hikino H, Rao GS: Coumestans as the main active principles of the liver drugs Eclipta alba andWedelia calendulacea. Planta Med 1986, 5:370-374.

7. Lin FM, Chen LR, Lin EH, Ke FC, Chen HY, Tsai MJ, et al: Compounds from Wedelia chinensis synergistically suppress androgen activity andgrowth in prostate cancer cells. Carcinogenesis 2007, 28:2521-2529.

8. Tewtrakul S, Subhadhirasakul S, Cheenpracha S, Karalai C: HIV-1 protease and HIV-1 integrase inhibitory substances from Eclipta prostrata. Phytother Res 2007, 21:1092-1095.

9. Kobori M, Yang Z, Gong D, Heissmeyer V, Zhu H, Jung YK, et al: Wedelolactone suppresses LPS-induced caspase-11 expression by directly inhibitingthe IKK complex. Cell Death Differ 2004, 11:123-130.

10. Ruhland A, Leal N, Kima PE: Leishmania promastigotes activate PI3K/Akt signalling to confer host cellresistance to apoptosis. Cell Microbiol 2007, 9:84-96.

11. Syed SD, Deepak M, Yogisha S, Chandrashekar AP, Muddarachappa KA D'Souza $P$, et al: Trypsin inhibitory effect of wedelolactone and demethylwedelolactone. Phytother Res 2003, 17:420-421.

12. Lawrence T, Willoughby DA, Gilroy DW: Anti-inflammatory lipid mediators and insights into the resolution of inflammation. Nat Rev Immunol 2002, 2:787-795

13. Tao JY, Zheng GH, Zhao L, Wu JG, Zhang XY, Zhang SL, et al: Antiinflammatory effects of ethyl acetate fraction from Melilotus suaveolens Ledeb on LPS-stimulated RAW 264.7 cells. J Ethnopharmacol 2009, 123:97-105.

14. Rietschel ET, Kirikae T, Schade FU, Mamat U, Schmidt G, Loppnow H, et al: Bacterial endotoxin: molecular relationships of structure to activity and function. FASEB J 1994, 8:217-225.

15. Carralot JP, Kim TK, Lenseigne B, Boese AS, Sommer P, Genovesio A, et al: Automated high-throughput siRNA transfection in raw 264.7 macrophages: a case study for optimization procedure. J Biomol Screen 2009, 14:151-160.

16. Nakagawa $S$, Arai $Y$, Kishida T, Hiraoka N, Tsuchida $S$, Inoue H, et al: Lansoprazole inhibits nitric oxide and prostaglandin $\mathrm{E}(2)$ production in murine macrophage RAW 264.7 cells. Inflammation 2012, 35:1062-1068.

17. Zhang YL, Dong C: MAP kinases in immune responses. Cell Mol Immunol 2005, 2:20-27.

18. Aderem A, Ulevitch RJ: Toll-like receptors in the induction of the innate immune response. Nature 2000, 406:782-787.

19. Kefaloyianni E, Gaitanaki C, Beis I, et al: ERK1/2 and p38-MAPK signalling pathways, through MSK1, are involved in NF-kappaB transactivation during oxidative stress in skeletal myoblasts. Cell Signal 2006, 18:2238-2251

20. Lee HS, Ryu DS, Lee GS, Lee DS, et al: Anti-inflammatory effects of dichloromethane fraction from Orostachys japonicus in RAW 264.7 cells: suppression of NF-kappaB activation and MAPK signaling. J Ethnopharmacol 2012, 140:271-276

21. Ji YY, Liu JT, Liu N, Wang ZD, Liu CH, et al: PPARalpha activator fenofibrate modulates angiotensin II-induced inflammatory responses in vascular smooth muscle cells via the TLR4-dependent signaling pathway. Biochem Pharmacol 2009, 78:1186-1197.

22. An H, Xu H, Zhang M, Zhou J, Feng T, Qian C, et al: Src homology 2 domain-containing inositol-5-phosphatase 1 (SHIP1) negatively regulates TLR4-mediated LPS response primarily through a phosphatase activityand PI-3K-independent mechanism. Blood 2005, 105:4685-4692.

23. Lee AK, Sung SH, Kim YC, Kim SG: Inhibition of lipopolysaccharide-inducible nitric oxide synthase, TNF-alpha and COX-2 expression by sauchinone effects on I-kappaBalpha phosphorylation, C/EBP and AP-1 activation. Br J Pharmacol 2003, 139:11-20.

24. Barnes PJ, Karin M: Nuclear factor-kappaB: a pivotal transcription factor in chronic inflammatory diseases. N Engl J Med 1997, 336:1066-1071.

25. Guha M, Mackman N: LPS induction of gene expression in human monocytes. Cell Signal 2001, 13:85-94.

26. Yu HY, Kim KS, Lee YC, Moon HI, Lee JH, et al: Oleifolioside A, a New Active Compound, Attenuates LPS-Stimulated iNOS and COX-2 Expression through the Downregulation of NF-kappaB and MAPK Activities in RAW 264.7 Macrophages. Evid Based Complement Alternat Med 2012, 2012:637512.

27. Stewart AG, Phan LH, Grigoriadis G, et al: Physiological and pathophysiological roles of nitric oxide. Microsurgery 1994, 15:693-702. 
28. Wang Z, Jiang W, Zhang Z, Qian M, Du B: Nitidine chloride inhibits LPSinduced inflammatory cytokines production via MAPK and NF-kappaB pathway in RAW 264.7 cells. J Ethnopharmacol 2012, 144(1):145-150.

29. Qiao J, Xu LH, He J, Ouyang DY, He XH: Cucurbitacin E exhibits antiinflammatory effect in RAW 264.7 cells via suppression of NF-kappaB nuclear translocation. Inflamm Res 2013, 62(5):461-469.

doi:10.1186/1423-0127-20-84

Cite this article as: Yuan et al:: Wedelolactone inhibits LPS-induced pro-inflammation via NF-kappaB Pathway in RAW 264.7 cells. Journal of Biomedical Science 2013 20:84.

\section{Submit your next manuscript to BioMed Central and take full advantage of:}

- Convenient online submission

- Thorough peer review

- No space constraints or color figure charges

- Immediate publication on acceptance

- Inclusion in PubMed, CAS, Scopus and Google Scholar

- Research which is freely available for redistribution 